\title{
Advance euthanasia directives and the Dutch prosecution
}

Corresponding Author: Jonathan A. Hughes, School of Law, Keele University, Staffordshire, ST5 5BG, United Kingdom. Telephone: +44 178273 4078. Email: j.a.hughes@keele.ac.uk

Key words: Euthanasia, Suicide/Assisted Suicide, Living Wills/Advance Directives, Criminal Law

Word count: 3528

Funding: none to report for this submission.

Acknowledgements: none.

Competing interests: none.

Ethics approval: none required as there are no human participants.

Contributorship: Jonathan Hughes is the sole contributor to this article. 


\begin{abstract}
:
In a recent Dutch euthanasia case, a woman underwent euthanasia on the basis of an advance directive, having first been sedated without her knowledge and then restrained by members of her family while the euthanasia was administered. This article considers some implications of the criminal court's acquittal of the doctor who performed the euthanasia. Supporters of advance euthanasia directives have welcomed the judgement as providing a clarification of the law, especially with regard to the admissibility of contextual evidence in interpreting advance euthanasia directives, but suggested that the law regarding advance euthanasia directives should be further relaxed to remove the requirement of current suffering, and that an unfortunate consequence of the prosecution is that it is likely to deter doctors from performing euthanasia even in more straightforward cases. This article argues that the court's endorsement of the use of contextual evidence is problematic, that the case for prioritising prior decisions over current interests has not been advanced by the discussion surrounding this case, and that worries about the alleged deterrent effect are not well-founded.
\end{abstract}

\title{
INTRODUCTION
}

In a recent Dutch euthanasia case, a woman referred to as Mrs A underwent euthanasia on the basis of an advance directive, having first been sedated without her knowledge and then restrained by members of her family while the euthanasia was administered.[1] This article examines the implications of the Dutch criminal court's acquittal of the doctor who performed the euthanasia in this case

Even before reaching the criminal court, this case generated considerable discussion. Earlier commentaries identified concerns relating to specific facts of the case. These included: a lack of clarity in the woman's advance euthanasia directive (AED) regarding the circumstances in which she intended euthanasia to be performed, and in particular a suggestion that she wished to determine the time of death herself; doubts about the woman's competence at the time her AED was written; uncertainty about whether she was suffering intolerably (as Dutch law requires) at the time the euthanasia was carried out; and the doctor's use of covert sedation in the face of spoken and physical indications that the patient may not have wished for euthanasia at the time it was carried out.[1-4] The commentaries also relate these concerns to more general 
arguments about the moral legitimacy of AEDs given the limits of a person's insight into their uncertain future circumstances and the changes that can occur in their personality and preferences between the writing of a directive and its execution.

Two of these specific concerns were upheld in the pre-criminal investigations of the case. Under Dutch law, all cases of euthanasia must be reported to the relevant Regional Review Committee. In this case, the committee held that the wording of the AED was insufficiently clear to constitute a valid request, and that the patient (who was restrained by her family after sitting up during the procedure, despite having been sedated) may have been resisting euthanasia. The medical disciplinary tribunal to which the case was subsequently referred similarly found that the AED was ambiguous, and that the doctor performing the euthanasia should have attempted to discuss her intention with the patient rather than sedating her.[5] In short, the criticisms were that the AED lacked clarity and that the no-longer-competent patient did not assent to its execution.

In contrast with the committee and the tribunal, the criminal court acquitted the doctor of wrongdoing, holding that the alleged lack of clarity in the AED was insufficient to undermine its validity given contextual evidence used by the doctor to inform its interpretation, and that oral confirmation of the patient's desire for euthanasia at the time it was carried out was neither possible, given her advanced dementia, nor required by law.[5]

A court decision does not, of course, settle either philosophical or empirical disputes beyond determining the law's attitude to them. In this instance there is room for critics of AEDs to argue that Dutch law rests on mistaken philosophical assumptions or that the court was mistaken in its assessment of how compliance with the relevant principles was or was not demonstrated by the facts of the case. Regarding the latter, it may be pointed out that that some of the facts asserted in the Regional Review Committee's report (for example, that subsequent to updating her AED Mrs A had said that she was "not yet" ready for euthanasia, and had described the euthanasia or assisted suicide procedure as "going too far"[1]) do not appear to have been addressed in the criminal court's judgment. ${ }^{i}$ However, my aim here is not to assess the court's interpretation of the facts but to examine some of the case's most important actual or claimed implications.

\footnotetext{
${ }^{i}$ At least, these facts do not appear in Asscher and van de Vathorst's account of the case, on which I am relying.
} 
In so doing, I will have particular regard to the claims made by Asscher and van de Vathorst: first, that the verdict is a confirmation and clarification of the law permitting AEDs, especially with regard to the admissibility of contextual evidence in interpreting them (which Asscher and van de Vathorst view as a positive development); second, that there is a case for further relaxation of the criteria for carrying out euthanasia based on an advance directive, by removing the requirement of current suffering; and third, a worry about doctors being deterred from carrying out euthanasia, "even for other, far less controversial cases". I will argue that Asscher and van de Vathorst establish neither the desirability of admitting contextual evidence nor that the case is likely to have an undesirable deterrent effect, and that their account of the case does not advance the case for prioritising prior wishes over current interests.

\section{CONTEXTUAL INTERPRETATION}

According to Asscher and van de Vathorst, the court's ruling that an AED that lacks clarity may be interpreted "contextually", taking account of conversations between patient and doctor at the time the AED was written, "helps to overcome one of the intrinsic difficulties of drafting an AED, namely to be clear enough for the performance of euthanasia, and not too restrictive."

The difficulty to which this points is a familiar tension between specificity and inclusiveness: an advance directive (whether relating to euthanasia or some other intervention) needs to specify the action that it authorises or refuses, and the circumstances in which it does so, narrowly enough that it isn't mistakenly taken to justify decisions that the patient would not have endorsed, but broadly enough that it is not invalidated by factors that the patient would have considered irrelevant. It is not clear, however, that the lack of clarity alleged in Mrs A's AED was of this nature: rather, the question asked by critics of the decision to execute the AED was whether it was intended as an advance directive at all, or whether, given its references to dying "when I think the time is right" and "at my request", it was merely expressing the desire to be offered the opportunity to request euthanasia while still having capacity.

Either way, the suggestion that conversations between patients and doctors can provide clarity that is not possible in a written AED does not stand up to scrutiny. If oral statements made by a patient in the course of such conversations can clarify their intentions, then it is not clear why they could not be incorporated into a better-drafted version of the AED. It may be that the conversations of the type that Mrs A's doctors reported to the court can help to elicit details about the patient's preferences that are likely to be missing from a statement composed in the 
absence of such conversations. This only means, however, that what I shall call a naïve statement supplemented by evidence from conversations with the doctor is likely to be a better reflection of the patient's intentions than the naïve statement alone. It does not entail that the combination of naïve statement and contextual evidence is better than a clear and detailed written statement drawn up following such conversation and with the help of someone with appropriate expertise and experience. Given the risks involved in a doctor or a court relying on remembered conversations (which may not be remembered correctly, or at all), there is at least a pro tanto reason for preferring the statement produced with expert help to the naïve statement interpreted in the light of the doctor's recollections. If it is objected the court need not rely on the doctor's memory as the doctor will have made a record of their conversation, then this concedes that the clarifications elicited conversationally can be captured in written form.

Asscher and van de Vathorst also write that the criminal court's verdict means that an "AED does not need to have the (legal) clarity" that was sought by the lower tribunals (the Regional Review Committee and the disciplinary tribunal), and that "not everyone needs to consult a lawyer to write an AED." But whether this is an advantage for the patient will depend on the balancing of benefits and risks.

On the positive side, not having to employ a lawyer is likely to save expense and might mean that more patients (who want to) are able to draw up AEDs. However, it is an exaggeration to suggest that if the court had not allowed contextual evidence this would mean that only an AED drawn up in consultation with a lawyer could be valid. A patient would still be free to formulate their own AED, although they would run the risk of it not being acted on if deemed insufficiently clear. A patient who employs a lawyer in these circumstances is paying to (hopefully) reduce that risk. Allowing contextual evidence to be used also reduces the risk of an AED not being acted on, without the expense of a lawyer. However, it does not remove that risk altogether, since there is no guarantee that the recollections of doctors or others will be sufficient to resolve the meaning of an unclear AED to the satisfaction of the courts. So, a patient wanting to be sure that their AED is acted on would be well-advised to consult a lawyer (or other relevant expert) anyway.

Moreover, allowing contextual evidence introduces its own risks for the patient, since a doctor's recollections may be inaccurate. Another doctor or a court relying on them may draw mistaken conclusions about the patient's intentions. There is therefore a possibility that euthanasia is carried out in circumstances where the patient would not have intended it, or that 
it is not carried out where the patient would have intended it. So, again, a patient seeking to reduce the risk of their wishes not being carried out would be well-advised to seek expert help in drawing up their AED in a way that captures the details that would otherwise be vulnerable to the vagaries of a doctor's interpretation and memory. Allowing family recollections as contextual evidence introduces still more risk of mistaken interpretation, due to the conflicts of interests to which family members may be subject.

None of this is to say that doctors should not be permitted to use contextual evidence in interpreting an AED, or that the courts should not take it into account in judging the legality of a doctor's actions. If an AED is open to different interpretations and the patient no longer has the capacity to clarify it, then it may be better to consider contextual evidence than to ignore it. But there is also good reason to be cautious about such evidence and for patients writing an AED to consider (and to be encouraged to consider) seeking expert help. Whether or not allowing contextual evidence is good policy will depend on the balance of benefits and risks, and at the policy level the relevant risks will include the possibility that by allowing poorlydrafted AEDs to be salvaged, the permitting of contextual evidence will disincentivise good drafting and the use of expert help.

\section{PERSONAL IDENTITY}

Another key ethical issue concerning AEDs, as mentioned above, is the change in a patient that can occur between the writing of an AED and the occurrence of the circumstances that will trigger its execution. Asscher and van de Vathorst write:

\footnotetext{
The core question here is whether one should follow the wishes of the then-self as put down in the AED or follow the apparent interests of the person with dementia. Some claim the now-self is a new person, based on the huge changes in psychological identity, and that this new and vulnerable person should be protected even from his former wishes. ... Alternatively, it can be argued that the opposition between the now-self versus the then-self is a false dichotomy. If one accepts the person with dementia as the same person as before, because the person is the same character in one ongoing life story with one narrative identity, it is not implausible to take account of the wishes expressed before.
}

There are, as this passage acknowledges, two issues here. First, there is a question of identity: whether a person whom dementia has left with few memories and changed personality, preferences and values is the same person as the former occupant of their body. If the answer to that is "no", then Asscher and van de Vathorst's description of a person being "protected 
from his former wishes" does not literally make sense, since it will be a different person's wishes that may determine the fate of the person with dementia. As Buchanan puts it, advance directives in these circumstances will not be "vehicles for self-determination", but "sinister devices to subjugate other persons."[6] Only if personal identity is preserved does the second question - how to balance a patient's current interests and wishes against the wishes they expressed when they had full capacity - even arise. ${ }^{\text {ii }}$

The question of whether personal identity is preserved in situations where AEDs are used is both philosophical (concerning the criteria for personal identity) and empirical (concerning the extent to which psychological connections are retained or lost). Asscher and van de Vathorst do not engage with the substance of these arguments but they do contend that, in acquitting the doctor in the case of Mrs A, the court has settled the position of the law on this matter:

The verdict affirms that for the law the now-self and the then-self are the same person, otherwise AEDs or any other advance directive could never be valid.

This, however, is too general a conclusion to draw from a single case. The fact that the court found Mrs A's AED to be valid shows only that in the eyes of the law a person can retain their identity after losing the capacity to make end of life decisions, not that they necessarily do. Whether there may be other cases, involving more severe cognitive decline, in which personal identity is lost, is not determined by the verdict in this one case. In fact, a stronger conclusion concerning the preservation of personal identity can be inferred from the Dutch euthanasia statute independently of this case, since the statute (Termination of Life on Request and Assisted Suicide (Review Procedures) Act, 2002, section 2(2)) explicitly gives legal force to advance directives without any qualifications as to the narrative or psychological continuity needed to underpin it.[7] The criminal court's judgement therefore does not alter the law's position on the question of the personal identity of patients with dementia.

\section{CURRENT INTERESTS VS PRIOR WISHES}

If we grant that in a case like that of Mrs A, sufficient psychological continuity exits to maintain personal identity, then the question arises of how to balance the wishes previously expressed

\footnotetext{
${ }^{\text {ii }}$ For brevity I set aside the scenario in which individual undergoing euthanasia is not only not the same person as the one who wrote the AED but not a person at all. Buchanan's view is that acting on an AED may be justified in such a case, but I would contend that his argument for this mistakenly equates a human non-person with a mere object.
} 
in an AED against the patient's current interests. Some commentators have seen this case as vindicating previous concerns that AEDs might lead to patients being killed against what appear to be their current wishes or interests on the basis of their prior decisions.[1]

Asscher and van de Vathorst believe such concerns to be misplaced, for two reasons. First, they argue that under Dutch law, "[i]n order for a physician to perform, euthanasia, he or she must be convinced that the patient in question is suffering unbearably and hopelessly at the time of the euthanasia" and that "no-one had doubts about the suffering in this case."

Whether Mrs A's suffering was "unbearable" might be questioned given her previously quoted comments that she was "not yet" ready for euthanasia and considered it to be "going too far" and the view of one of the doctors who assessed her that she was at times (especially during her husband's visits) cheerful.[1,8] However, for Asscher and van de Vathorst this should not matter ethically, since for them "the (apparent) experiential interests of a person should not over-rule the existential interests laid down in an AED." Thus, even if Mrs A had been like "Margo", the subject of Dworkin's partly fictionalised case of a woman with severe dementia who is carefree and cheerful in her current, albeit limited, condition, they would hold that it was right to carry out euthanasia according to her previously-stated wishes.[9]

For Dworkin, the prior wishes reflecting the patient's autonomous deliberation should be respected because they represent "critical interests", which shape, and give meaning and coherence, to our lives in a way that mere "experiential interests" do not. Asscher and van de Vathorst use the language of critical versus experiential interests but do nothing to address criticism of Dworkin's position, which has argued that this distinction is less clear and less important to many people's conception of their own good than Dworkin supposes.[10] They argue, in what seems a remarkably weak justification for ending someone's life contrary to what appear to be their current wishes, that because the (experiential) interests of a person with advanced dementia can only be inferred from observation, it is "impossible to exclude that it might still be in the person's interests to no longer exist". They write that because a person with severe dementia is no longer able to reflect on his interests and weigh them himself, this should have happened when they still had the capability:

During the drawing up of an AED the person would have (or should have) considered that he might be an apparently happy person with advanced dementia, and still considered this not to be the end of his narrative that he wanted. 
This echoes Dworkin's focus on narratives and endings, but the parenthetical phrase indicates that we cannot rely on an AED being based on such an overarching perspective (again indicating the importance of clarity and advantages of an AED being composed with expert guidance), and ignores plausible doubts about the extent to which someone who has not yet experienced the impact of severe dementia can reflect authoritatively on the quality of life of a person like Margo.

The case for allowing an AED to override the current interests or wishes of a person with dementia is therefore not advanced either by the court's judgment, which accepted (whether rightly or not) that Mrs A's current interests aligned with her previously-stated wishes, or by Asscher and van de Vathorst's analysis.

\section{DETERRING DOCTORS}

A final issue to consider is whether, notwithstanding its outcome, the prosecution may deter other doctors from performing euthanasia, making it harder for patients to access assistance in dying. It is not clear whether Asscher and van de Vathorst raise this issue merely as an observation or whether it is intended to have normative implications (for example for future decisions about whether to prosecute). Either way, the evidence for this being a serious concern is weak.

As Asscher and van de Vathorst state, this is the first prosecution of a doctor for euthanasia since it was legalised in 2002. It is, moreover, a case that clearly pushes at the boundaries of the legal criteria for lawful euthanasia, as illustrated by the findings of the Regional Review Committee and the medical tribunal, and by Asscher and van de Vathorst's own view that the case clarified the law with respect to the use of contextual evidence. Nevertheless, the court found in favour of the doctor. Given all this, it seems unlikely that doctors practicing euthanasia in cases that fall clearly within the legal parameters need worry about prosecution.

The only concrete evidence that Asscher and van de Vathorst offer for a deterrent effect is that the prosecution resulted in the Dutch Centre for Euthanasia Expertise receiving more requests for advice, including advice concerning straightforward cases. However, if doctors are uncertain about the application of the legal criteria then it is surely a good thing that they obtain advice, and where the advice is that the case is legally unproblematic it is hard to see how they will be deterred. 


\section{CONCLUSION}

The most important implication of this case concerns the court's approval of the use of contextual evidence in interpreting AEDs. This is a significant development of the law, but, I have argued, one which brings risks as well as benefits, at both individual and policy levels. The problem it addresses would be addressed more reliably and with less risk by encouraging patients to obtain expert advice when drawing up AEDs. This development therefore should not be given an unqualified welcome, but should be regarded with great caution.

The court's confirmation of the legal status of AEDs and its implication that personal identity can survive a loss of mental capacity are unsurprising given the explicit role for AEDs specified in the Dutch euthanasia statute.

Due to Mrs A's reported comments and the use of sedation and restraint, the case raises the moral question of how the current interest of a non-competent patient should be weighed against the wishes that they expressed when they had capacity, as discussed in commentaries published prior to the criminal court hearing. Asscher and van de Vathorst use the criminal court judgment as an occasion to state their support for a Dworkinian policy that would, contrary to the current law, allow euthanasia on the basis of an AED even where this would go against what appear to be the current wishes or interests of the individual. However, neither their discussion nor the court's verdict adds substantially to existing debate about this controversial view.

Finally, there is not sufficient evidence to support the suggestion that this prosecution will deter doctors from performing euthanasia or to suggest that the prosecution should not have been brought.

\section{REFERENCES}

1 Miller DG, Dresser R, Kim SYH. Advance euthanasia directives: a controversial case and its ethical implications. Journal of Medical Ethics 2019;45:84-9. doi:10.1136/medethics2017-104644

2 Menzel PT. AEDs are problematic, but Mrs A is a misleading case. Journal of Medical Ethics 2019;45:90-1. doi:10.1136/medethics-2018-104780

3 Wall J. 'Mrs A': a controversial or extreme case? Journal of Medical Ethics 2019;45:778. doi:10.1136/medethics-2019-105351 
4 Jongsma KR, Kars MC, van Delden JJM. Dementia and advance directives: some empirical and normative concerns. Journal of Medical Ethics 2019;45:92-4. doi:10.1136/medethics2018-104951

5 Asscher ECA, van de Vathorst S. First prosecution of a Dutch doctor since the Euthanasia Act of 2002: what does the verdict mean? Journal of Medical Ethics 2019;46. doi:10.1136/medethics-2019-105877

6 Buchanan A. Advance Directives and the Personal Identity Problem. Philosophy and Public Affairs 1988;17:277-302.

7 The World Federation of Right to Die Societies. Dutch law on Termination of life on request and assisted suicide (complete text). https://www.worldrtd.net/dutch-lawtermination-life-request-and-assisted-suicide-complete-text (accessed 4 Feb 2020).

8 Kim SYH, Miller DG, Dresser R. Response to: 'Dementia and advance directives: some empirical and normative concerns' by Jongsma et al. Journal of Medical Ethics 2019;45:95-6. doi:10.1136/medethics-2018-105031

9 Dworkin R. Life's Dominion: an argument about abortion and euthanasia. London: : Harper Collins 1993.

10 Dresser R. Dworkin on dementia: Elegant theory, questionable policy. The Hastings Center Report; Hastings-on-Hudson 1995;25:32-8. 